\begin{tabular}{c} 
Volume and Issues Obtainable at Center for Sustainability Research and Consultancy \\
Journal of Business and Social Review in Emerging Economies \\
ISSN: 2519-089X (E): 2519-0326 \\
Volume 6: Issue 2 June 2020 \\
JSR \\
Journal homepage: www.publishing.globalcsrc.org/jbsee \\
\hline
\end{tabular}

\title{
Promotion of Anti-Social and Anti-Cultural Behavior by Private Television Dramas in Pakistan
}

\author{
${ }^{1}$ Rukhsana Faiz, ${ }^{2}$ Sumera Khalid, ${ }^{3}$ Tahir Mahmood \\ ${ }^{1}$ M.Phil, Department of Communication Studies, Bahauddin Zakariya University, Multan Pakistan, \\ rukhsana.faiz70@gmail.com
}

${ }^{2}$ Lecturer, Department of Mass Communication, Women University Multan, Pakistan, sumerakhalid8@gmail.com

${ }^{3}$ Assistant Professor, Department of Communication Studies, Bahauddin Zakariya University, Multan Pakistan, tahirmahmood@bzu.edu.pk

\begin{tabular}{l}
\hline ARTICLE DETAILS \\
\hline History \\
Revised format: May 2020 \\
Available Online: June 2020 \\
\\
\hline Keywords \\
Antisocial, Anti cultural, \\
violence, bad language, \\
dressing, Pakistani TV drama, \\
ARY Digital, Hum TV \\
\hline JEL Classification \\
M1, M21
\end{tabular}

ARTICLE DETAILS

Revised format: May 2020

Available Online: June 2020

\section{Keywords}

Antisocial, Anti cultural, violence, bad language, dressing, Pakistani TV drama, JEL Classification

$M 1, M 21$

\begin{abstract}
The study is based on content analysis of four dramas from Pakistani private television networks. Two dramas from Hum TV and two dramas from ARY Digital were selected using convenient sampling technique. The variable of violence, language and dressing was developed and content was coding into developed categories. The content analysis showed that there is a significant use of violent behaviors in the dramas of both channels. The study found that there is abundant use of fouls language or verbal violence in the dramas as well. The promotion of foreign or western culture was clearly evident in the dramas of both TV channels. The analysis found that there was clear promotion of antisocial and anti-cultural elements by these dramas.
\end{abstract}

Corresponding author's email address: tahirmahmood@bzu.edu.pk

Recommended citation: Faiz, R., Khalid, S., and Mahmood, T. (2020). Promotion of anti-social and anti-cultural behavior by private television dramas in Pakistan. Journal of Business and Social Review in Emerging Economies, 6(2), 761-780

\section{Introduction}

Kling \& Geoffrey (2000) found that use of electronic communications technologies both in science and in society has increased significantly and all electronic media have an important role to play in different fields. Shoemaker \& Reese (1991) observed that television is a form of domestic cinema, Which produce a wide sort of programs, for individuals of all ages, interface \& bunches but in some cases, T.v Programs promote violent behavior, incorporate such fictional characters or scenes which promote violence against gender, single individual, or group. Cantor \& Nathanson (1997) found that TV portrays a several ways of viciousness through many programs. The TV content (both news and entertainment) contain an elevated level of brutality that is continuous over time. Even though year-to-year program to program variances do happen the general picture is one of significant violence.

Robinson \& Martin (2008) found that people are entertained at home by Television programs. These programs are as diverse as groups of people with different interest and ages. This variety of programs include violence against gender or group of people and this shows the negative side of society. Perry et al (1997) observed that the reason behind the uncontrolled entertainment provided by Television programs is to increase their viewership in order to earn more and 
more money and fame. Programs in which women is portrayed as a show-piece to get attention, are the result of this greed of popularity.

Cashmore (2002) found that television is such a type of medium which communicates in an effective and spellbounding manner to provide information and spread awareness about the situations around the globe. It can capture the viewer's mind to mold their behavior and attitude. Raza, Bakar \& Mohamad (2018) found that content of television do have impact on the audience. Audience get the message from television and take influence in their day to day life decisions.

\subsection{Culture}

Grondelaers (1995) established that Culture is mixture of different patterns, beliefs, characteristics share by common people among the society. Ingold (2002) found that every culture is an introduction of people who own it. People use values and belief of their culture to live their lives by a specific pattern and thus share a sense of unity. Culture also share social aspects as its language, norms, different patterns, rules of living etc.

\subsection{Pakistani Culture}

Human make culture and culture modify human. Pakistani culture represents its people because it somehow reflects the morals and beliefs of its own creation. Unfortunately Pakistani culture has fallen prey to a disease called invasion and trying to mix some other cultures within their own culture.

\subsection{What is Anti Social Behaviour?}

Anti-Social behaviour is against principles of society. when a person manipulates and distress another individual. A person with Anti-Social behaviour can make anyone,s life as miserable as hell due to his/her poor conduct.

\subsection{TV Drama}

TV drama are series of show mainly intended to focus on realistic development of a character who maybe dealing with emotional trauma. In drama story seems like real journey in which audience travel along the characters feel empathy.

\section{Literature review}

John Hartley, (1996) puts forward his idea of television as a communicating device between classes, ethnic groups and nations. Television gives its viewers a chance to be a part of symbolic communities. These communities represent relationship between certain stars, music and fans. Moreover, the domains of drama, documentaries and current affairs produces politics in this community.

Rogers, (2000) proved that mass media has influenced many countries. People started taking the necessary health measures and adopted a different reproductive behavior. Thussu, (2000) wrote an article, Indian media- from colonial to global. He stated that despite of the counter cultural flow of products shown by Indian networks like Zee, US-Led western media domination has not finished. Muhammad (2003) observed that Indian and western TV channels are a threat to Pakistani culture. In this regard, some precautions are to be made to preserve and strengthen the nation and its culture. Change that spreads positivity should be encouraged only.

Levy (1982) observed in his study on the behavioral change that television casts a shadow on human behavior which is hard to understand. But, at the same time, it is an important problem that needs to be solved. The understanding of the effects can yield better production of the television content. Raza, Bakar \& Mohamad (2019) found that It is understood that the effects are there and are very deep. Television effects the behavior of adults and children in different manners.

Smyth (1954) reported that violence has become an integral part of television dramas, especially those dramas which are directed at women. This violence results in aggressive attitudes against women. Torture is being witnessed at the societal level due to these representations of violence. This torture may be psychological as well as physical. According to a report, 430,000 sexual assaults against women are conducted, annually. 
Andreason (1995) found that investigating the effects of television on human behavior are most difficult. The effects of media on behavior of human are so diverse and so variant in nature that it can not be concluded anything like scientists do in natural science. Social science community today, is trying to figure out what effects are imparted on human behavior by TV, exactly.

Aksoy \& Robins (2003) Television Audience are always observing what they see on TV. During viewing various shows, they embrace distinctive things from these dramatizations. Gentzkow and Shapiro (2004) Discover that TV Viewership in Muslim World Influences demeanor toward the west. Jamie (1993) shown the negative effect on Asia by western media which is in the end adding to change in culture. A huge majority of viewers experienced negative change in their way of life.

George Gember \& Gross (1976) violence theory, it evaluated that the normal introduction to excessively rough \& criminal tainted sensational world conditioned in watchers an intemperate uneasiness approximately individual security. The viewers learn from stereotyped substance designs on TV \& draw inductions from them. that they at that point sum up to this present reality they expected that TV in an especially, with its clearly standard portrayal of abusive behavior can have major cognitive impacts on viewers` faith and concerns about crime/violence behavior.

Uma (1984) expressed that "The media will in general offer uniform and moderately consensual adaptations of the social reality and their crowd is acculturated likewise. There are a few sorts of broad communications yet one of the most mainstream and appealing medium is the TV. Raza et al (2020) established that all types of contents of television, drama or advertising, are influencing the behavior of the audience. The viewers are the consumers and the television content are the product.

Mahvish (2006) focuses out the domination of leading countries of the world on Pakistani society. These impacts alter our fashion sense, eating habits and our house designing. Drama Culture is affecting our Social Relationships/culture. Routine life is likewise changing in negative manner on the name of style. Anderson (2007) found that there's solid relationships between hostility and the seeing of savage/brutal media.

\section{Significance of Study}

This Study is content analysis of two drama serial and these Dramas were on aired from two leading private channel of Pakistan ARY Digital and Hum TV. Researcher has selected dramas of ARY Digital and Hum TV because they have great viewership (Tooba, 2015). Most of the housewives use to watch prime time dramas on national TV. In the past dramas were source of entertainment but now a days, they have different impacts on lives of viewers. They may lead the viewers towards violence, crime and other social/antisocial behaviors. Savage (2008) found that some TV serial are creating anti-social activities in the society such as domestic violence, physical violence, psychological violence and bad impact on social norms and values.

This study will investigate the intensity of violence, usage of language and use of anti-cultural dressing, which is shown in dramas in high rates. Now a days a lot of violence is shown in prime time dramas. I took these dramas because they have great viewership and all the elements are shown in these dramas. Both print and electronic media have a certain freedom to transmit contents based on information and entertainment as well. One of the important responsibility of media is also to keep an eye on the social and moral values. Jamal et al (2018) established that media can be a good agent of social change and a bad source of cultural invasion. Many private channels in Pakistan are enjoying working freedom. Through this research we want to know that how electronic media is presenting the western culture in our Pakistani dramas. How our electronic media is influence by the other culture.

\section{Research Questions}

RQ1: What is the comparison of use of antisocial and anti cultural elements in dramas of different private TV channels of Pakistan?

\section{Hypothesis}

H1: Pakistani dramas are likely to be promoting violence in society. 
H2: Pakistani dramas are likely to be promoting offensive language in society.

H3: It is more likely that Pakistani dramas are not promoting foreign or western culture through use of dressing.

\section{Statement of Problem}

These both channels ARY Digital and HUM TV are the leading channels of Pakistani electronic media. The rating of both channels is very high. The viewership of these channels is increasing day by day. That's why; the dramas of these channels are very popular among women. The dramas of both channels have great intensity of violence such as physical violence which is categorize to slap, push, and drag into other type of violence. Similarly the bad language and vulgar dressing. Dramas are showing all these things in high rates. These dramas are destroying the roots of our culture.

Tariq (2005) found in a research on Pakistani national Television and a private entertainment channel (Geo TV), that PTV (Pakistan Television) is presenting the culture of Pakistan in dramas and other contents, more effectively. PTV presents national culture in almost all types of programs. This presentation of Pakistani culture is the reason of popularity ans credibility of PTV dramas and shows. On the other hand Geo TV is not promoting Pakistani cultural in true spirit. The culture shown in GEO TV dramas is alien and it it representational of Pakistani culture.

Khanum \& Khan (2000) found that the language which is used in Pakistani dramas is not appropriate. There was a time when famous Pakistani Dramas make people to sit at homes without moving from their place and watch them. But these days the present dramas don't have this type of everlasting impression. Now days a lot of violence is shown in our private channel drama especially in prime time dramas. Sometimes very cheap and vulgar language is used which is against our moral values. Farooq (2020) found that, now a days Pakistani people are influenced by the western culture and especially in terms of dressing. Pakistani people are adopting the fashion of west and other developed countries. This adoption is without any care of the cultural values of Pakistan and without considering the exact body type for which that specific fashion is introduced.

Pervez et al (2009) established that there are different types of violence in the TV programs e.g. symbolic violence, written, violence physical violence, verbal violence, violent gestures etc. Psychological violence is appearing most frequently and being noticed most rarely among all types of violence. This type of violence is committed by almost all types of characters against all types of characters.on of the very important form of psychological violence is Sexual harassment. This type of harassment takes place anywhere either at home or workplace in TV dramas. Women may face different types of molestation, pushing, gestures, jokes or comments in TV shows.

types of molestation, pushing, gestures, jokes or comments in TV shows.

\section{Objectives}

1. To find out the intensity of violence in our society through Dramas.

2. To investigate whether these dramas are promoting vulgarity through dressing.

3. Are these dramas promoting vulgarity through language in society?

4. To investigate whether these dramas are promoting western culture in Pakistan.

\section{Operational Definition}

8.1 Violence: When a person hurts himself of other persons with physical or psychological means, may using verbal or physical abuse that may cause insult or injury, death or any kind of pressure to the affectee is called violence. Different types of violence cause different consequences in the society.

8.2 Slap: To beat someone on face with anger.

8.3 Push: To apply pressure against for the purpose of moving.

8.4 Drag:To pull some one with force.

8.5 Language: The method of human communication, either spoken or written, consisting of the use of words in a structured and conventional way. It is categorize into harsh, bold, abuse etc, used in dramas. 
8.6 Language "A way of human communication"

8.7 Abuse: use bad words for some one

8.8 Harsh words: To call someone with anger

8.9 Bold words: The words beyond the limits

8.10 Dressing: To wear clothes of a certain kind or style or a style of clothing.

8.11 Sleevless: A part of a garment that does not covers all or part of an arm

8.12 Tights: these are kind of cloths which are close fitting. Through which body parts should prominent.

8.13 Saree: traditional dress of India, unstitched, uncut through which body parts should prominent.

\section{Methodology}

This Study is based on content analysis of two drama serial time period of 13 weeks. This study aims at perception about antisocial elements in Pakistani private channel dramas. This is based on watching the 2 dramas of both channel ARY Digital and Hum TV dramas.

\subsection{Content analysis}

Nature of the mass media effects can be studied by using content analysis method of research. Content analysis is a formal system for doing something that we all do informally rather frequently, drawing conclusion from observation of content. Krippendorff (1980) found that inferences can be made by distinguishing specified characteristics of a content using systematic and objective approach. Added that results of content analysis should be predictive of something that is, in theory, observable, or aid conceptualizing reality.

\subsection{Variables}

Three variables, violence, dressing and language were developed for content analysis. Each variable was divided into three categories and content was coded accordingly into following categories:

1: Violence into

(Slap, push and drag)

2: language into

(Harsh words, bold word and abuse)

3: Dressing into

(Sleeveless, tights and saree)

\subsection{Universe of Study}

All dramas of private television channels of Pakistan were the population of the study.

\subsection{Sample}

Sample was taken on convenient bases. Accessing the all episodes of two dramas of ARY Digital (Kahani Aik Raat $\mathrm{Ki}$, Kala Jadoo) and 2 dramas of Hum TV (Humnasheen, Rehaii) were easy to find for study.

\subsection{Unit of Analysis}

Every single scene of an episode was taken as a unit of analysis.

\section{Results}




\section{ARY drama (Kala Jadoo):}

\section{Violence:}

Table1: Showing Violence in ARY Digital Drama Kala Jadoo

\begin{tabular}{|l|l|l|l|}
\hline Sr. No. & Slap & Push & Drag \\
\hline Episode 1 & 1 & 2 & 1 \\
\hline Episode 2 & 1 & 1 & 2 \\
\hline Episode 3 & No & 3 & 2 \\
\hline Episode 4 & 2 & No & 1 \\
\hline Episode 5 & 2 & 2 & No \\
\hline Episode 6 & 3 & 1 & 1 \\
\hline Episode 7 & 2 & 3 & 1 \\
\hline Episode 8 & No & No & 1 \\
\hline Episode 9 & 1 & 1 & No \\
\hline Episode 10 & No & 1 & 2 \\
\hline Episode 11 & 1 & 2 & 1 \\
\hline Episode 12 & 1 & No & No \\
\hline Episode 13 & No & No & 1 \\
\hline Total & 14 & 16 & 13 \\
\hline
\end{tabular}

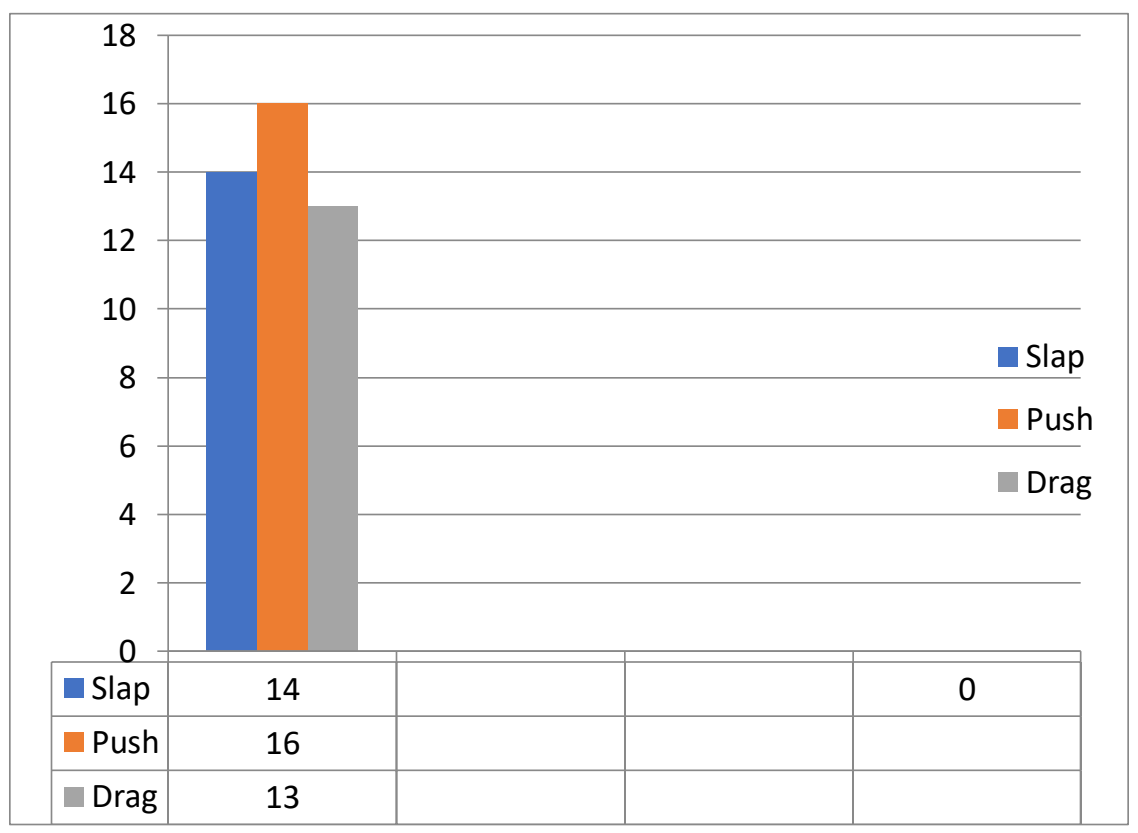

Chart 1: Graphical Representation of Violence in ARY Digital Drama Kala Jadoo

\section{Interpretation}

Analysis of table 1 reveals that lot of violence was shown in this drama. The intensity of violence increase day by day in our dramas which create tension among the audience. Now days our dramas become source of frustration only. A lot of physical violence is shown in this drama. In this drama objects were push lot of time. In 13 episodes the objects were 16 times push and 14 times slap and 13 times drag.

\section{Language}

Table: 2 showing bad language in ARY Digital drama serial Kala Jadoo

\begin{tabular}{|l|l|l|l|}
\hline Sr. No. & Abuse & $\begin{array}{c}\text { Harsh } \\
\text { Words }\end{array}$ & Bold Words \\
\hline Epi1 & 4 & 2 & 1 \\
\hline Epi2 & 2 & 1 & 3 \\
\hline Epi3 & 2 & 3 & 2 \\
\hline Epi4 & 2 & 1 & 1 \\
\hline Epi5 & 3 & 1 & 2 \\
\hline
\end{tabular}




\begin{tabular}{|l|l|l|l|}
\hline Epi6 & 1 & 2 & 1 \\
\hline Epi7 & 1 & 1 & 2 \\
\hline Epi8 & 3 & 1 & 1 \\
\hline Epi9 & 2 & No & 1 \\
\hline Epi10 & 1 & 2 & 3 \\
\hline Epi11 & 2 & 3 & 1 \\
\hline Epi12 & 1 & 1 & No \\
\hline Epi13 & No & No & 1 \\
\hline Total & $\mathbf{2 4}$ & $\mathbf{1 8}$ & $\mathbf{1 9}$ \\
\hline
\end{tabular}

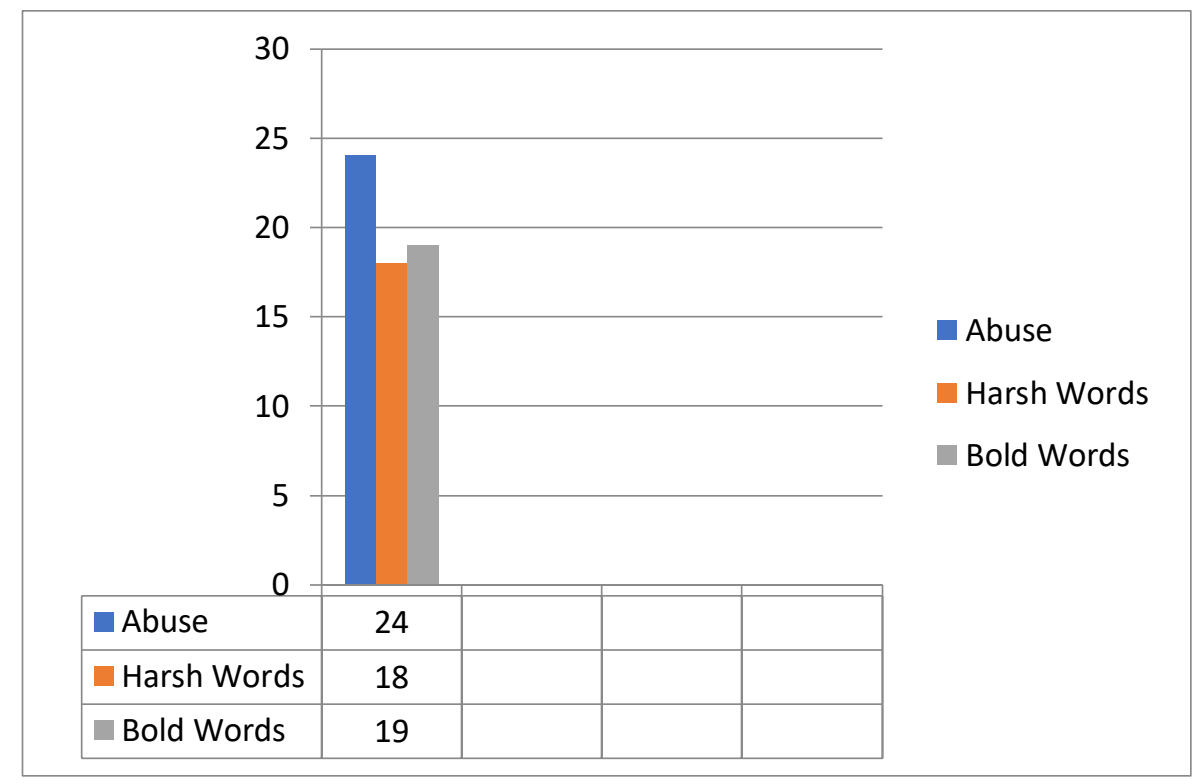

Chart: 2 Graphically showing bad language in ARY Digital drama serial Kala Jadoo

\section{Interpretation}

Study of table 2 reveals that the language which is used in present dramas is not good. In this drama very cheap language is used. Very abusive and harsh language is used. In Kala Jadoo abusive language is used in high intensity. It has shown that in 13 episodes 24 times abusive words, 18 times harsh words and 19 times bold words are used in this drama.

\section{Dressing}

Table 3: Showing vulgar dressing in ARY Digital drama serial Kala Jadoo

\begin{tabular}{|l|l|l|l|}
\hline Sr. No. & Sleeveless & Tights & Saree \\
\hline Epi1 & 3 & 2 & 3 \\
\hline Epi2 & 2 & 1 & 1 \\
\hline Epi3 & 2 & 2 & 2 \\
\hline Epi4 & 1 & 1 & 1 \\
\hline Epi5 & 3 & 2 & No \\
\hline Epi6 & 2 & 2 & 1 \\
\hline Epi7 & 3 & 2 & 1 \\
\hline Epi8 & 2 & 1 & No \\
\hline Epi9 & 1 & 1 & 2 \\
\hline Epi10 & 2 & 2 & No \\
\hline Epi11 & 1 & 3 & 1 \\
\hline Epi12 & 1 & 1 & 1 \\
\hline Epi13 & 2 & 2 & 1 \\
\hline Total & $\mathbf{2 5}$ & $\mathbf{2 2}$ & $\mathbf{1 4}$ \\
\hline
\end{tabular}




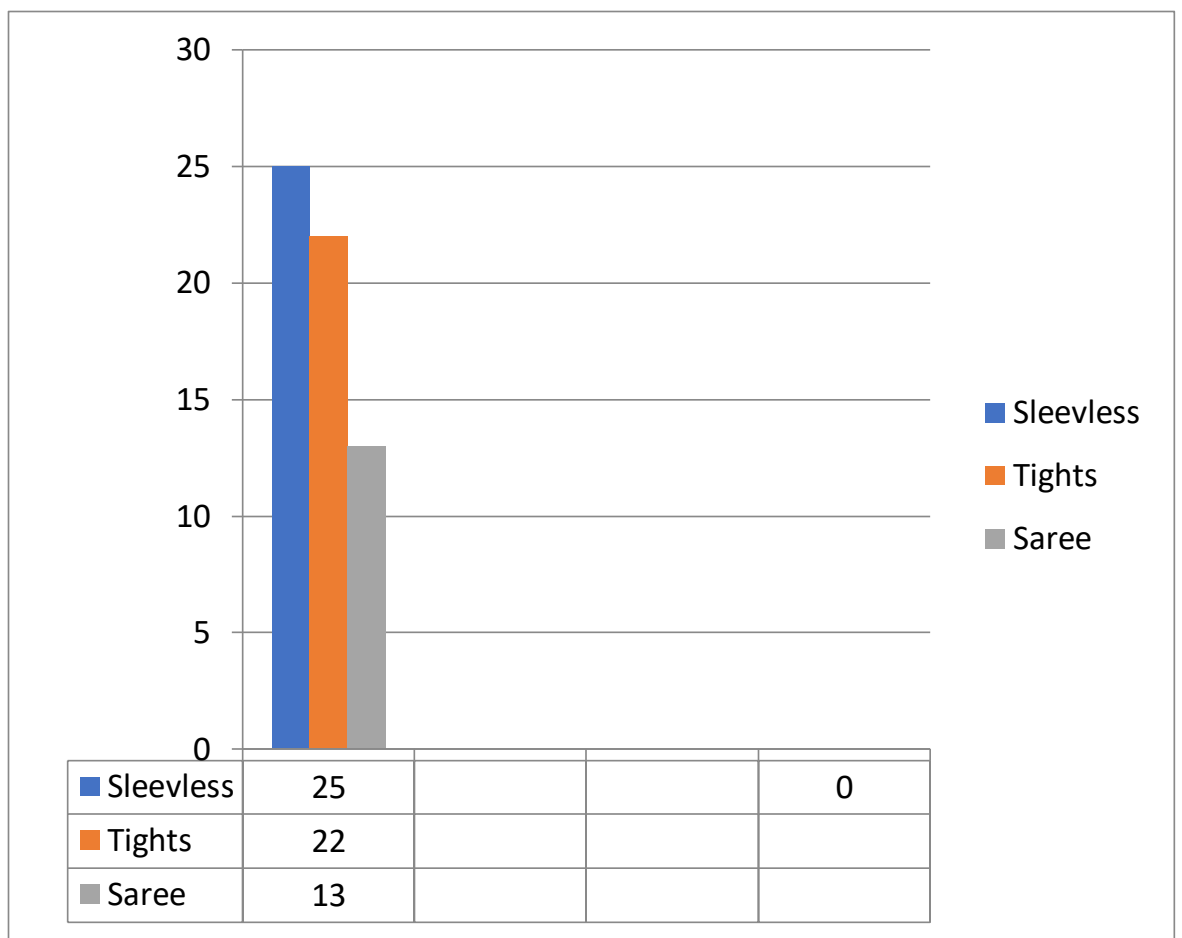

Chart 3: Graphically showing vulgar dressing in ARY Digital drama serial Kala Jadoo

\section{Interpretation}

Analysis of Table 3 reveals that the dressing which is used in this drama is very vulgar. Mostly dresses which are used in this drama are sleeveless so the ratio of sleeveless dressing is high in this drama. In 13 episodes 25 times sleeveles $s$ dresses, 22 times tights and 14 times saree are shown in this drama.

\section{ARY Digital drama (Kahani Aik Raat Ki)}

\section{Violence}

Table 4: showing violence in ARY Digital drama Kahani Aik Raat Ki

\begin{tabular}{|l|l|l|l|}
\hline Sr. No. & Slap & Push & Drag \\
\hline Epi1 & 1 & No & 1 \\
\hline Epi2 & No & 1 & 2 \\
\hline Epi3 & No & 2 & 1 \\
\hline Epi4 & 1 & 1 & 1 \\
\hline Epi5 & 1 & 2 & 1 \\
\hline Epi6 & 2 & 1 & No \\
\hline Epi7 & 2 & 1 & 2 \\
\hline Epi8 & No & No & 1 \\
\hline Epi9 & 2 & 1 & 1 \\
\hline Epi10 & 1 & 2 & 2 \\
\hline Epi11 & 1 & 2 & 1 \\
\hline Epi12 & 1 & 1 & No \\
\hline Epi13 & No & No & 1 \\
\hline Total & $\mathbf{1 2}$ & $\mathbf{1 4}$ & $\mathbf{1 4}$ \\
\hline
\end{tabular}




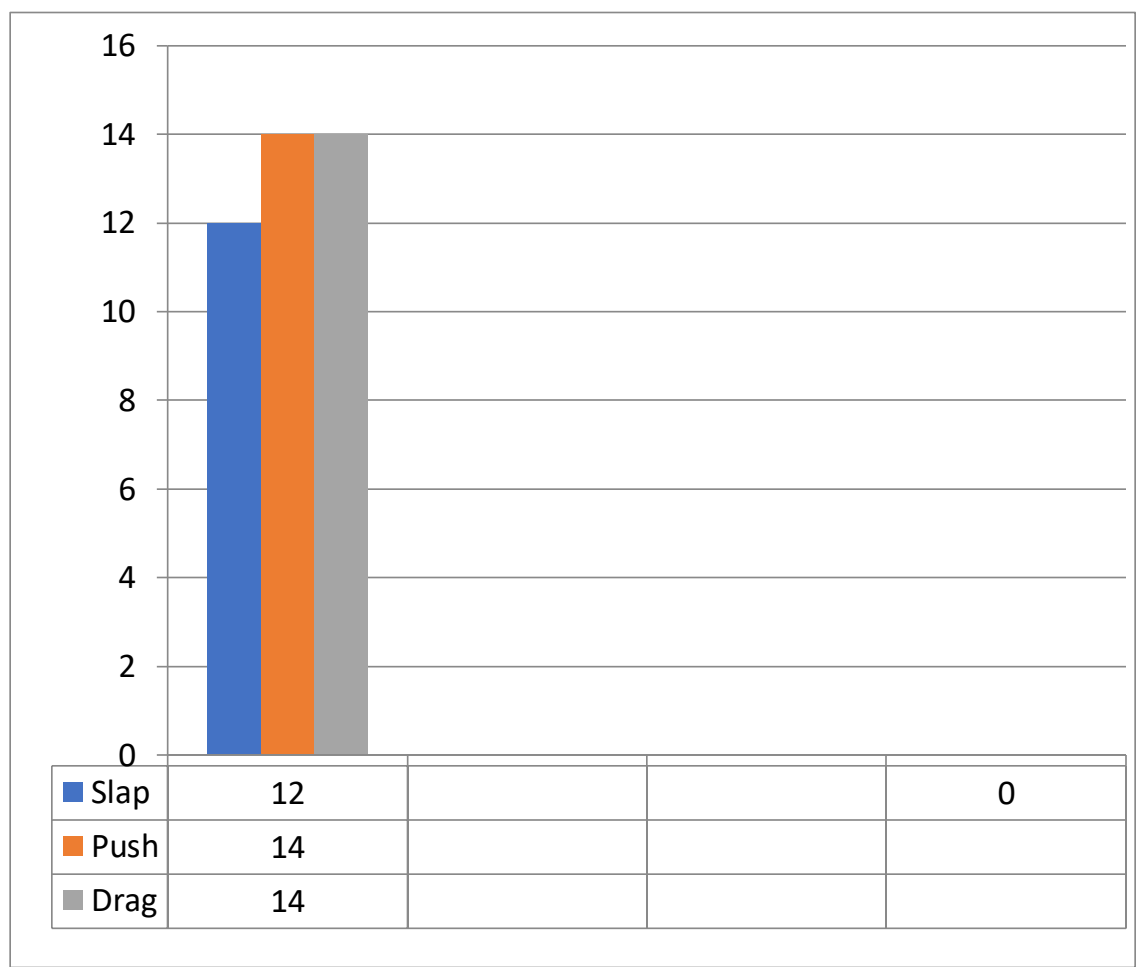

Chart 4: Graphically showing violence in ARY Digital drama Kahani Aik Raat Ki.

\section{Interpretation}

Table 4 reveals that there is a lot of violence which has shown in the drama. Now day's dramas only create tension by showing a lot of violence in dramas there is a lot of physical violence in this drama. The physical violence is in the form of slap, drag and push. In 13 episodes 12 times slap 14 times push and 14 times drag was shown in drama Kahani Aik Raat Ki.

\section{Language}

Table 5: showing the bad language in ARY Digital drama Kahani Aik Raat Ki

\begin{tabular}{|l|l|l|l|}
\hline Sr. No. & Abuse & $\begin{array}{c}\text { Harsh } \\
\text { Words }\end{array}$ & Bold Words \\
\hline Epi1 & 2 & 3 & 2 \\
\hline Epi2 & 1 & 1 & 1 \\
\hline Epi3 & 2 & 3 & 2 \\
\hline Epi4 & 1 & 1 & 1 \\
\hline Epi5 & 2 & 2 & 1 \\
\hline Epi6 & 1 & 2 & 1 \\
\hline Epi7 & 3 & 1 & 2 \\
\hline Epi8 & 2 & 1 & No \\
\hline Epi9 & 2 & 1 & 1 \\
\hline Epi10 & 3 & 2 & 2 \\
\hline Epi11 & 2 & 2 & 1 \\
\hline Epi12 & 1 & 1 & No \\
\hline Epi13 & No & No & 1 \\
\hline Total & $\mathbf{2 2}$ & $\mathbf{2 0}$ & $\mathbf{1 5}$ \\
\hline
\end{tabular}




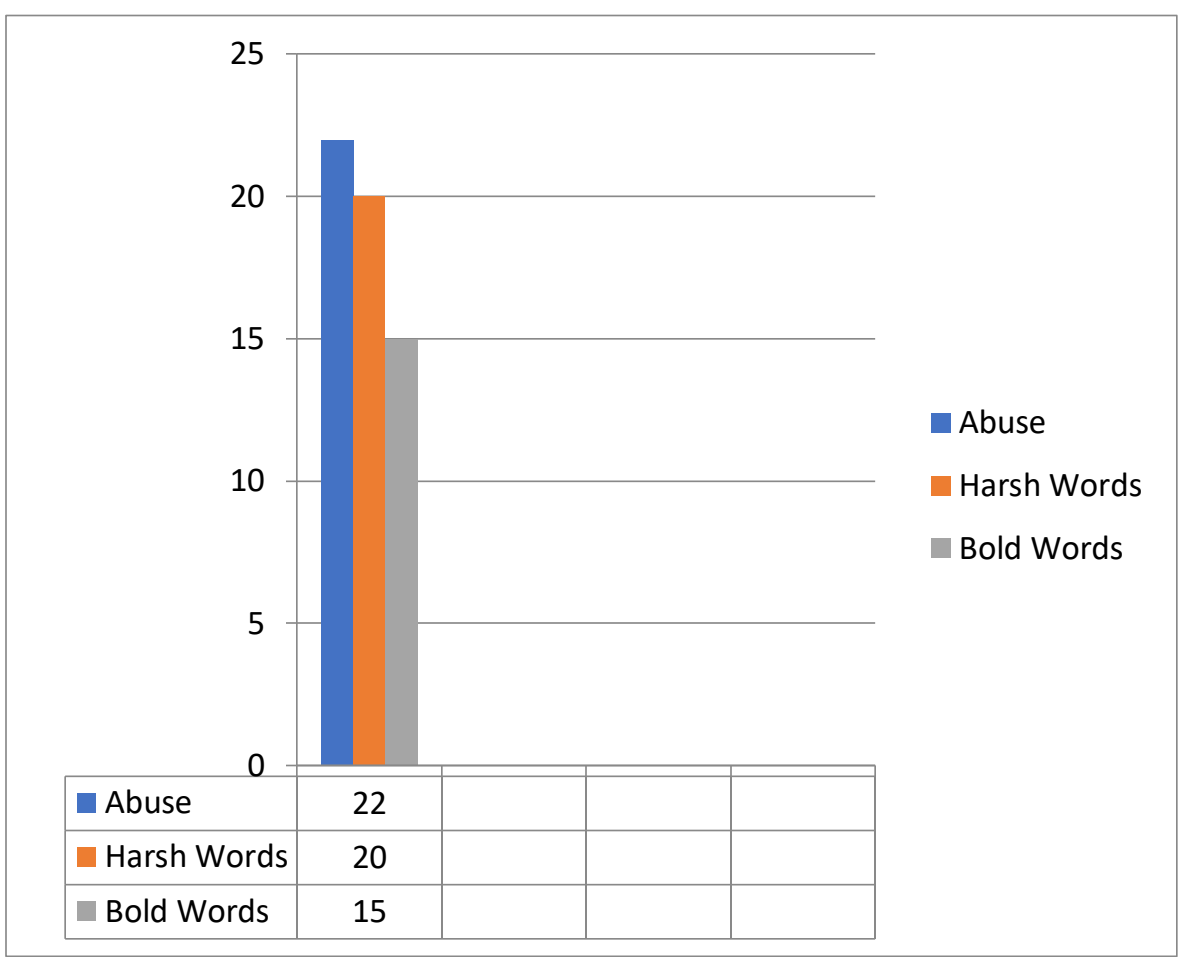

Chart 5: Graphically showing the bad language in ARY Digital drama Kahani Aik Raat Ki

\section{Interpretation}

The table 5 shows that how much bad language was use in this drama. Language was not good as there were cheap and vulgar words in the dialogues. This diagram shows that abusive language use in the drama in high intensity. It has shown that in 13 episodes 22 times abusive words, 20 times harsh words and 15 times bold words are used in this drama.

\section{Dressing}

Table 6: Showing vulgar dressing in ARY Digital drama Kahani Aik Raat Ki.

\begin{tabular}{|l|l|l|l|}
\hline Sr. No. & Sleeveless & Tights & Saree \\
\hline Epi1 & 5 & 3 & 2 \\
\hline Epi2 & 3 & 1 & 1 \\
\hline Epi3 & 2 & 2 & 3 \\
\hline Epi4 & 1 & 1 & 1 \\
\hline Epi5 & 3 & 1 & No \\
\hline Epi6 & 1 & 2 & 1 \\
\hline Epi7 & 3 & 2 & 1 \\
\hline Epi8 & 2 & 1 & No \\
\hline Epi9 & 1 & 3 & 2 \\
\hline Epi10 & 3 & 2 & 2 \\
\hline Epi11 & 3 & 2 & 1 \\
\hline Epi12 & 1 & 1 & 1 \\
\hline Epi13 & 2 & 2 & No \\
\hline Total & $\mathbf{3 0}$ & $\mathbf{2 3}$ & $\mathbf{1 5}$ \\
\hline & & & \\
\hline
\end{tabular}




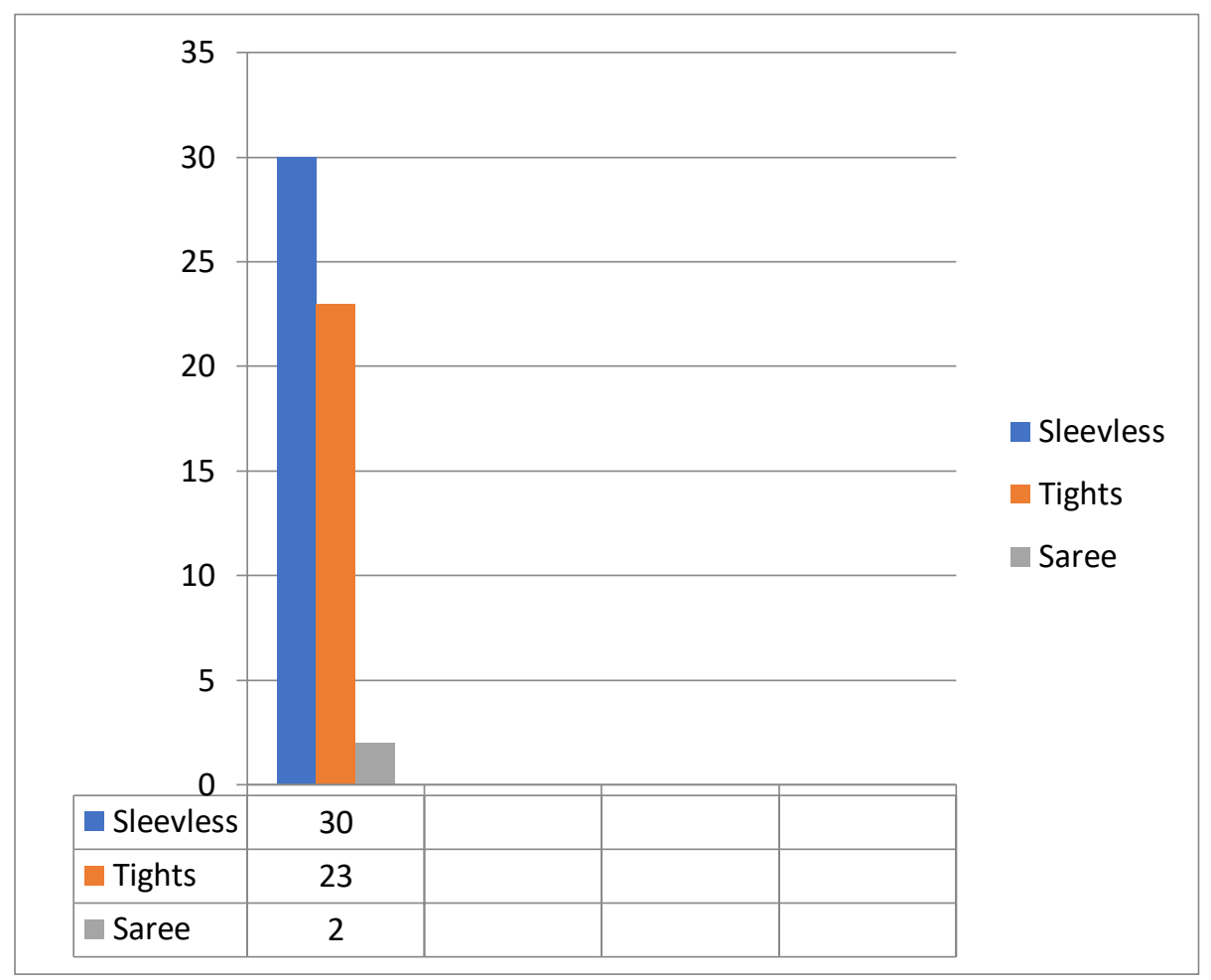

Chart 6: Graphically showing vulgar dressing in ARY Digital drama Kahani Aik Raat Ki.

\section{Interpretation}

Study of table 6 reveals that the dressing which is used in the drama was so vulgar. Now days in our dramas girls wear sleeveless clothes, jeans and capris. Which affects our norms and moral values? In this drama 30 times sleeveless dresses, 23 times tights are used and 15 times saree. And this ratio increased day by day in our dramas.

\section{HUM TV drama serial (Humnasheen)}

\section{Violence}

Table 7: Showing violence in HUM TV drama Hamnasheen.

\begin{tabular}{|l|l|l|l|}
\hline Sr. No. & Slap & Push & Drag \\
\hline Epi1 & No & 2 & 1 \\
\hline Epi2 & 1 & 1 & No \\
\hline Epi3 & No & 3 & 2 \\
\hline Epi4 & 2 & No & 1 \\
\hline Epi5 & 1 & 2 & No \\
\hline Epi6 & 2 & 2 & 1 \\
\hline Epi7 & 2 & 3 & No \\
\hline Epi8 & 1 & No & 1 \\
\hline Epi9 & 1 & 1 & 1 \\
\hline Epi10 & No & 2 & 2 \\
\hline Epi11 & 1 & 2 & 1 \\
\hline Epi12 & 1 & 1 & 1 \\
\hline Epi13 & No & No & No \\
\hline Total & $\mathbf{1 2}$ & $\mathbf{1 9}$ & $\mathbf{1 1}$ \\
\hline
\end{tabular}




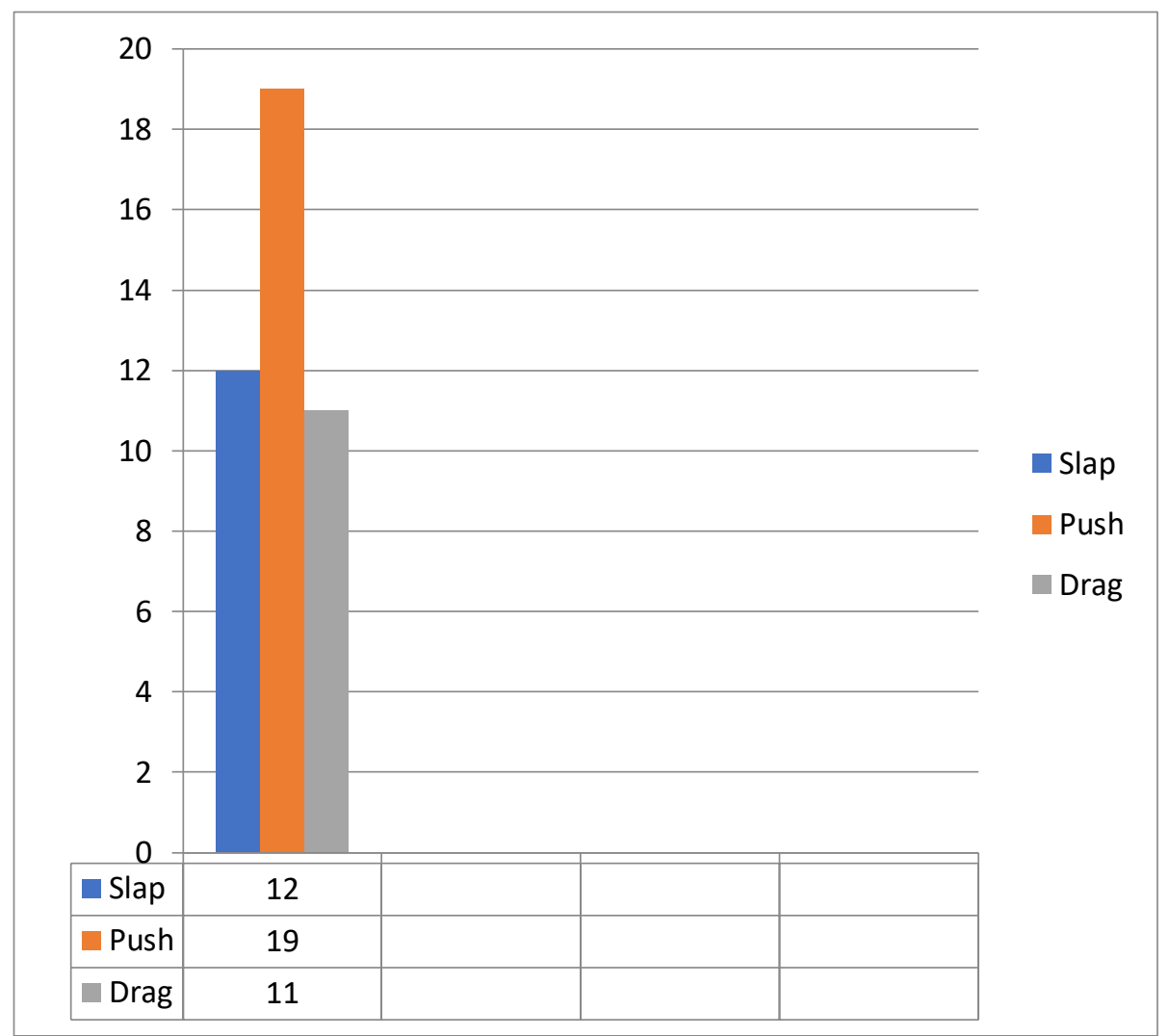

Chart 7: Showing violence in HUM TV drama Hamnasheen.

Study of table 7 shows that there is a lot of violence in hum TV drama. There was a time when our dramas were source of entertainment but now days our dramas become the source of frustration. A lot of violence is shown is our dramas which create frustration among the audience. It is shows that in 13 episodes 12 times slap, 19 times push and 11 times drag shown in this drama.

\section{Language:}

Table 8: Showing bad language in HUM TV drama Humnasheen.

\begin{tabular}{|l|l|l|l|}
\hline Sr. No. & Abuse & $\begin{array}{c}\text { Harsh } \\
\text { Words }\end{array}$ & Bold Words \\
\hline Epi1 & 5 & 3 & 2 \\
\hline Epi2 & 2 & 1 & 1 \\
\hline Epi3 & 1 & 3 & 2 \\
\hline Epi4 & 2 & 1 & 1 \\
\hline Epi5 & 3 & 2 & 2 \\
\hline Epi6 & 1 & 2 & No \\
\hline Epi7 & 2 & 2 & 2 \\
\hline Epi8 & 3 & 1 & 1 \\
\hline Epi9 & 2 & No & 2 \\
\hline Epi10 & 1 & 2 & 3 \\
\hline Epi11 & 2 & 3 & 1 \\
\hline Epi12 & 1 & 2 & No \\
\hline Epi13 & No & No & 1 \\
\hline Total & $\mathbf{2 5}$ & $\mathbf{2 2}$ & $\mathbf{1 8}$ \\
\hline
\end{tabular}




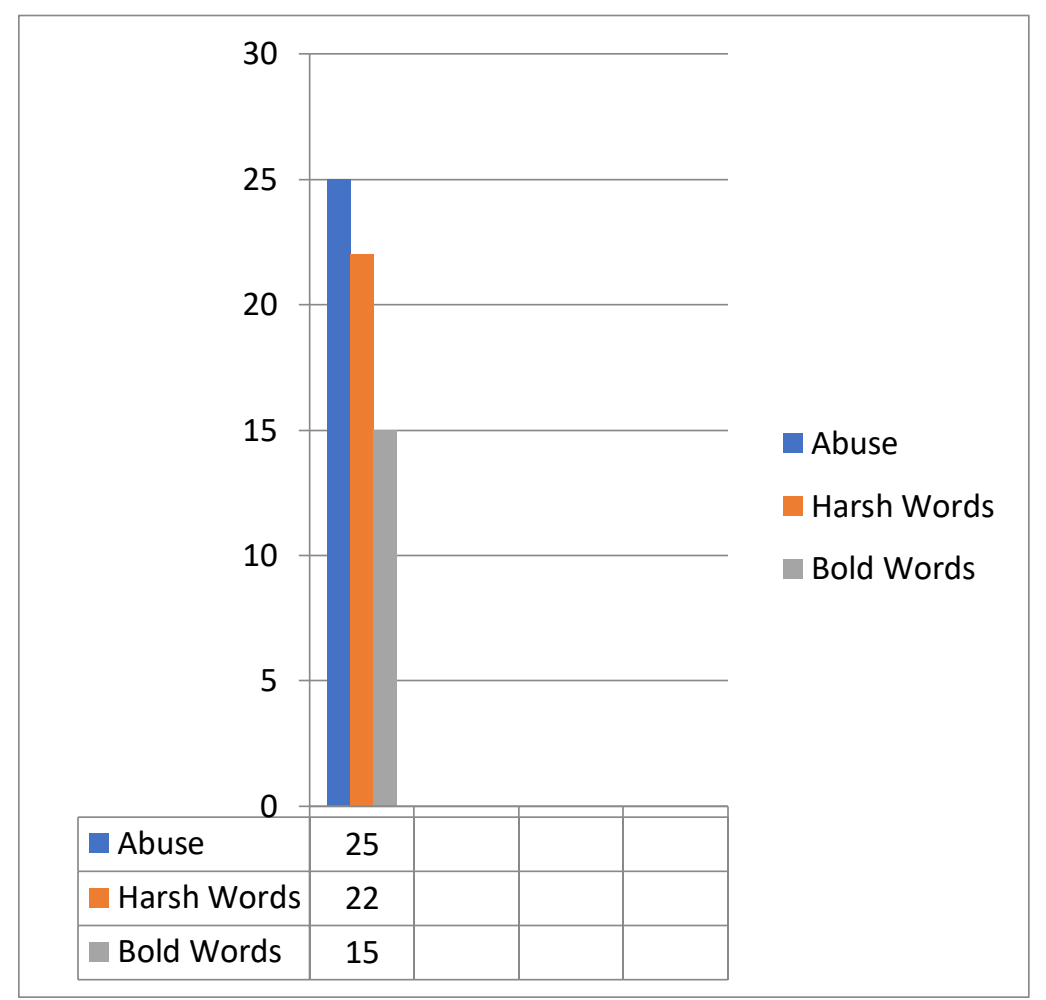

Chart 8: Graphically showing bad language in HUM TV drama Humnasheen.

\section{Interpretation}

Study of table 8 shows that how much bad language was used in this drama. There was a time when the stories and language of dramas were very strong. But in present the language of dramas is not good. A lot of abusive language used in this drama. The ratio of abusive language is very high in this drama. In 13 episodes 25 times abusive words, 22 times harsh words and 18 times bold words were used in drama serial "Humnasheen".

\section{Dressing}

Table 9: showing bad dressing in HUM TV drama Humnasheen

\begin{tabular}{|l|l|l|l|}
\hline Sr. No. & Sleeveless & Tights & Saree \\
\hline Epi1 & 5 & 3 & 2 \\
\hline Epi2 & 3 & 1 & 1 \\
\hline Epi3 & 2 & 2 & 3 \\
\hline Epi4 & 1 & 1 & 1 \\
\hline Epi5 & 3 & 1 & No \\
\hline Epi6 & 1 & 2 & 1 \\
\hline Epi7 & 3 & 2 & 1 \\
\hline Epi8 & 2 & 1 & No \\
\hline Epi9 & 1 & 3 & 2 \\
\hline Epi10 & 3 & 2 & 2 \\
\hline Epi11 & 3 & 2 & 1 \\
\hline Epi12 & 1 & 1 & 1 \\
\hline Epi13 & 2 & 2 & No \\
\hline Total & $\mathbf{3 0}$ & $\mathbf{2 3}$ & $\mathbf{1 5}$ \\
\hline
\end{tabular}




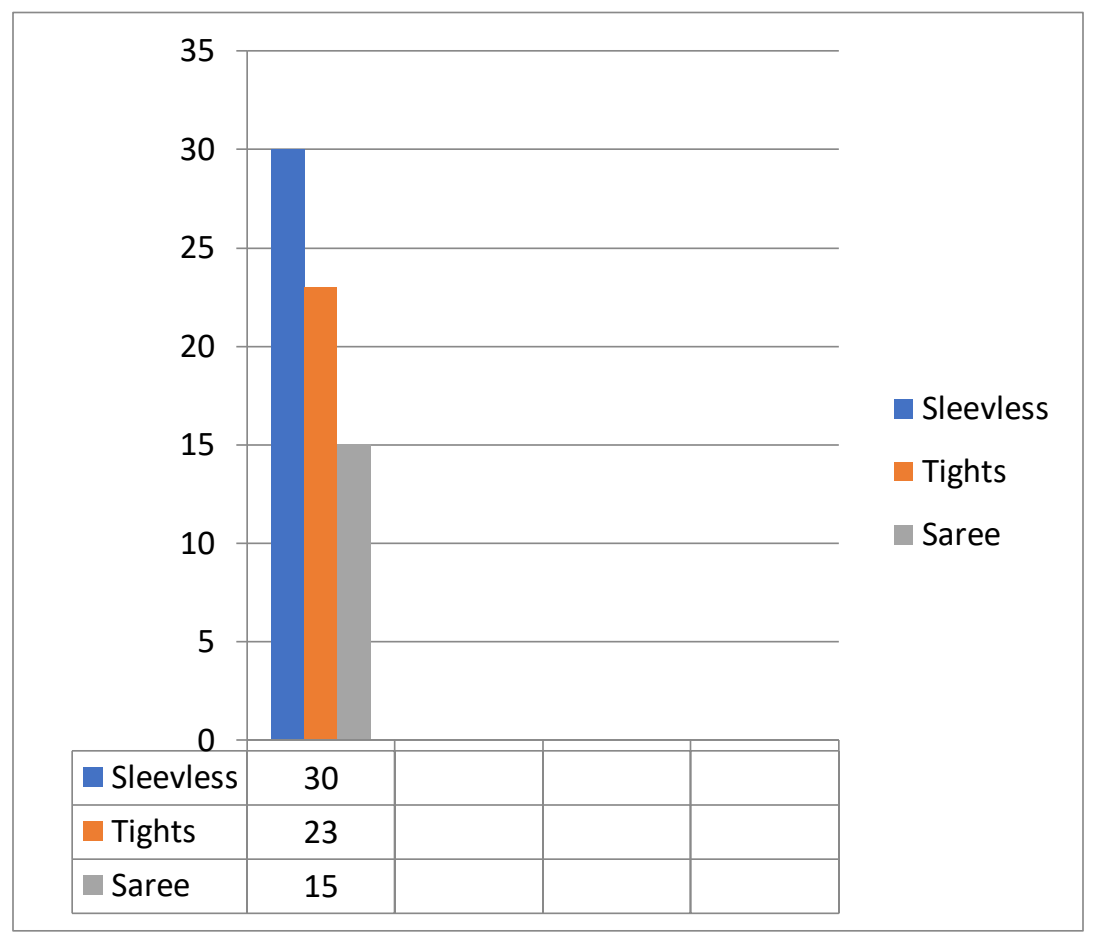

Chart 9: Graphically showing bad dressing in HUM TV drama Humnasheen.

\section{Interpretation}

Analysis of table 9 shows that the dressing used in this drama are not good. Now days in our dramas western dresses are used. Western culture is entered in our dramas through dressing the jeans capris are used in our dramas. The dresses which are used in this drama are mostly sleevless.In 13 episodes 30 times sleeveless, 23 times tights and 15 times saree was shown.

\section{Drama serial (Rehaii)}

\section{Violence}

Table 10: showing violence in HUM TV drama in Rehaii

\begin{tabular}{|l|l|l|l|}
\hline Sr. No. & Slap & Push & Drag \\
\hline Epi1 & 1 & No & 1 \\
\hline Epi2 & 2 & 2 & 2 \\
\hline Epi3 & 2 & 3 & 1 \\
\hline Epi4 & 1 & 2 & 1 \\
\hline Epi5 & 1 & 2 & 1 \\
\hline Epi6 & 3 & 1 & No \\
\hline Epi7 & 2 & 1 & 2 \\
\hline Epi8 & No & 2 & 1 \\
\hline Epi9 & 2 & 3 & No \\
\hline Epi10 & 2 & 2 & 2 \\
\hline Epi11 & 1 & 1 & 2 \\
\hline Epi12 & 1 & 2 & No \\
\hline Epi13 & No & No & No \\
\hline Total & $\mathbf{1 8}$ & $\mathbf{2 1}$ & $\mathbf{1 3}$ \\
\hline
\end{tabular}




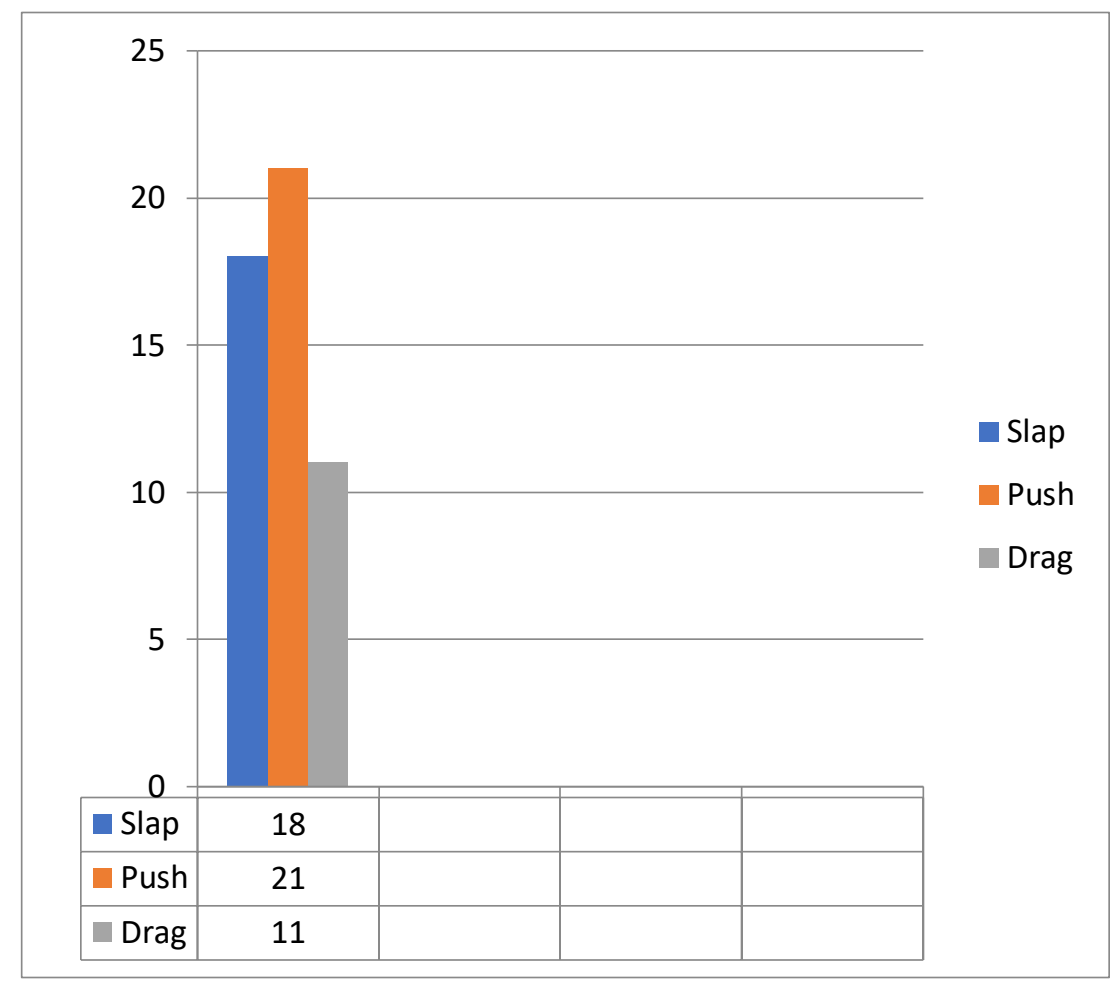

\section{Interpretation}

Chart 10: Graphically showing violence in HUM TV drama in Rehaii

Table 10 reveals that how much violence is shown in hum TV drama. There is lot of physical violence shown in drama in the form of pushes, slaps and drag. When audience watches this type of drama which has lot of violence they are only frustrated. Similarly in this drama lot of violence has shown. The ratio of slap is more than other physical violence It was shown that in 13 episodes 18 times slap, 21 times push and 13 times drag shown in this drama.

\section{Language}

Table 11: Showing bad language in HUM TV drama Rehaii.

\begin{tabular}{|l|l|l|l|}
\hline Sr. No. & Abuse & $\begin{array}{c}\text { Harsh } \\
\text { Words }\end{array}$ & Bold Words \\
\hline Epi1 & 3 & 2 & 2 \\
\hline Epi2 & 2 & 1 & No \\
\hline Epi3 & 1 & 3 & 2 \\
\hline Epi4 & 2 & 1 & 2 \\
\hline Epi5 & 3 & 3 & 1 \\
\hline Epi6 & 1 & 2 & 1 \\
\hline Epi7 & 2 & 3 & 2 \\
\hline Epi8 & 3 & 1 & 1 \\
\hline Epi9 & 2 & 2 & 1 \\
\hline Epi10 & 3 & 2 & 2 \\
\hline Epi11 & 2 & 3 & 1 \\
\hline Epi12 & 2 & 1 & No \\
\hline Epi13 & No & No & 1 \\
\hline Total & $\mathbf{2 6}$ & $\mathbf{2 4}$ & $\mathbf{1 6}$ \\
\hline
\end{tabular}




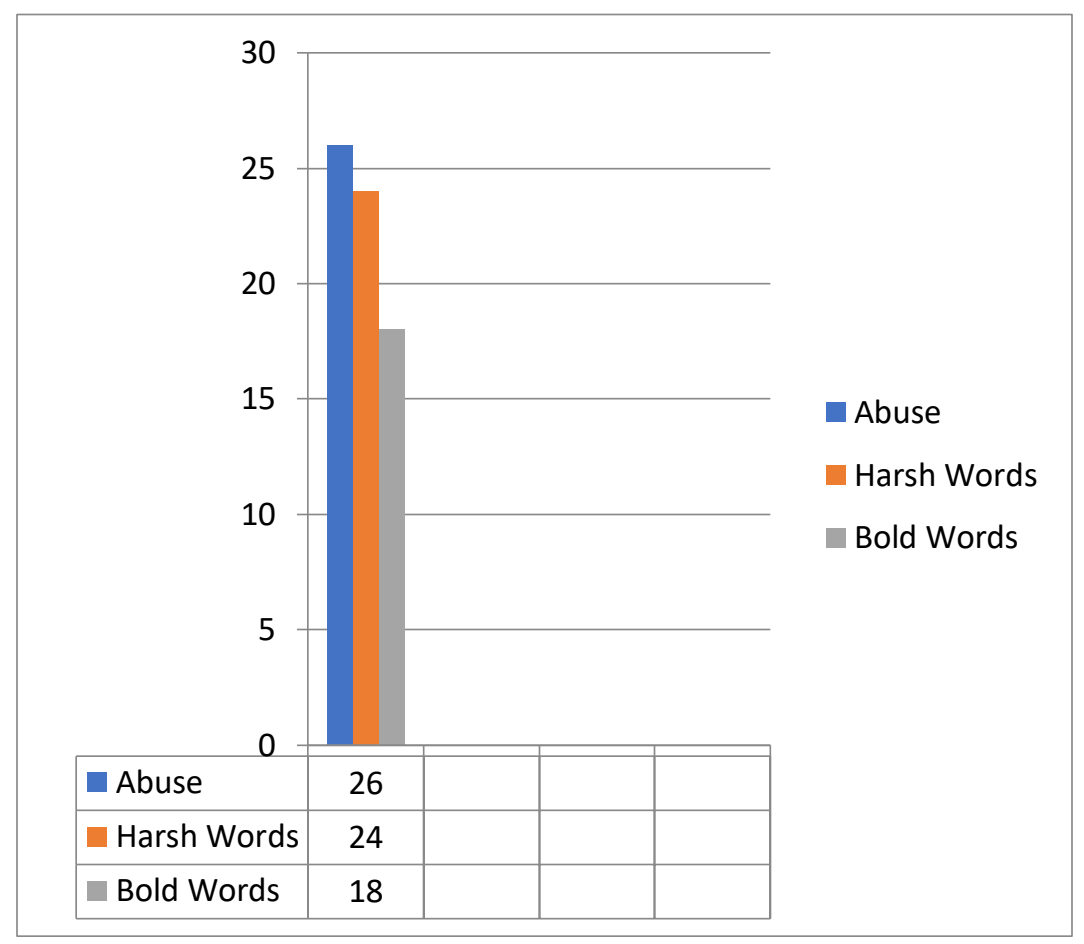

\section{Interpretation}

\section{Chart 11: Graphically showing bad language in HUM TV drama Rehaii.}

Analysis of table 11 reveals that the language of this drama is very bad and abusive. A lot of harsh words are used in the drama. Similarly a lot of bold words are also used but the intensity of abusive words was high. The ratio of abusive language is very high in this drama serial. In 13 episodes 26 times abusive words, 24 times harsh words and 16 times bold words were used in drama.

\section{Dressing}

Table 12: Showing vulgar dressing in HUM TV drama Rehaii.

\begin{tabular}{|l|l|l|l|}
\hline Sr. No. & Sleeveless & Tights & Saree \\
\hline Epi1 & 2 & 3 & 1 \\
\hline Epi2 & 2 & 2 & No \\
\hline Epi3 & 1 & 1 & 2 \\
\hline Epi4 & 1 & No & 1 \\
\hline Epi5 & 1 & 2 & No \\
\hline Epi6 & 1 & 1 & 1 \\
\hline Epi7 & 2 & 2 & 1 \\
\hline Epi8 & 2 & 1 & No \\
\hline Epi9 & No & 1 & 2 \\
\hline Epi10 & 1 & 2 & No \\
\hline Epi11 & 1 & 1 & 1 \\
\hline Epi12 & 2 & 1 & No \\
\hline Epi13 & 2 & 2 & 1 \\
\hline Total & $\mathbf{1 8}$ & $\mathbf{1 9}$ & $\mathbf{1 0}$ \\
\hline
\end{tabular}




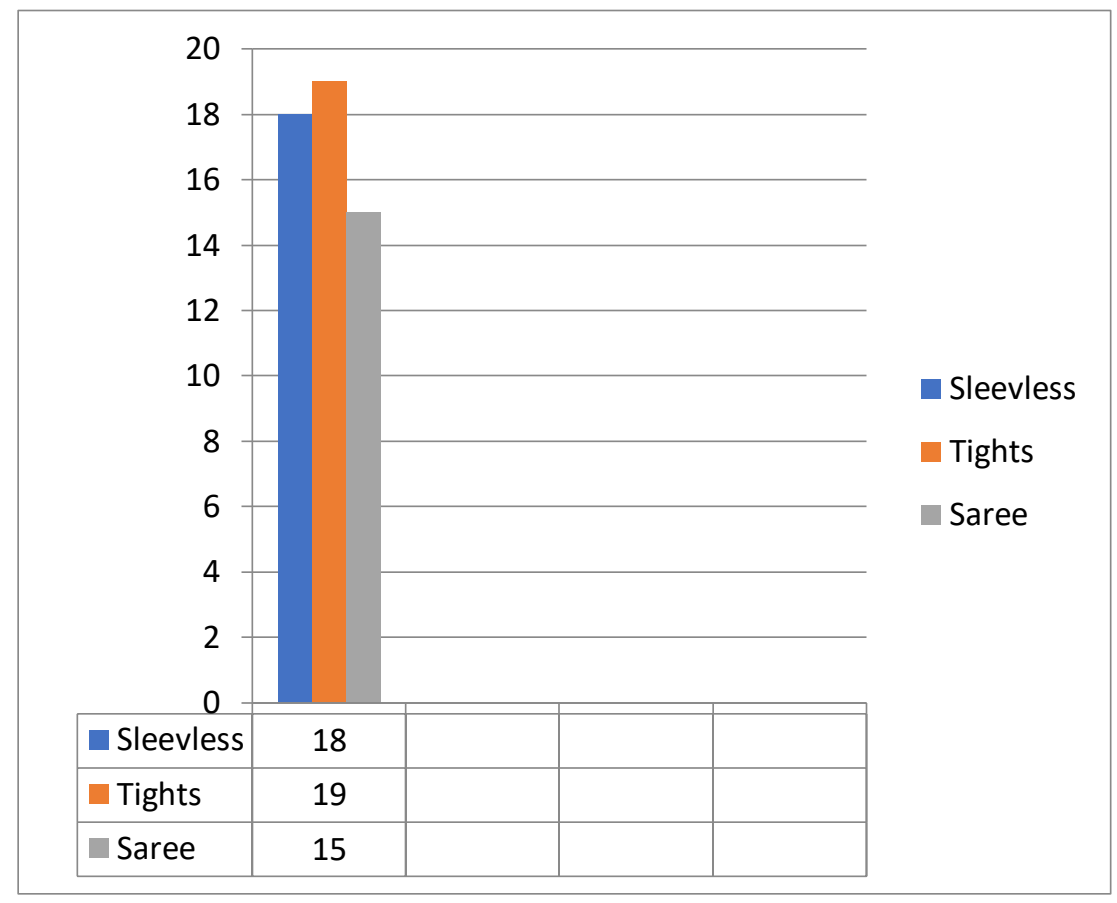

Chart 12: Graphically showing vulgar dressing in HUM TV drama Rehaii.

\section{Interpretation}

Table 12 shows that how much vulgar dressing was used in this drama.in this drama mostly girls were in sleeveless dresses and mostly were in jeans, Capri and saree. Although all the clothes which are used in this drama are very vulgar but the ratio of tights are very high in this drama. In 13 episodes 18 times sleeveless, 19 times tights and 10 times saree used in this drama.

\section{Comparison of HUM TV and ARY Digital dramas}

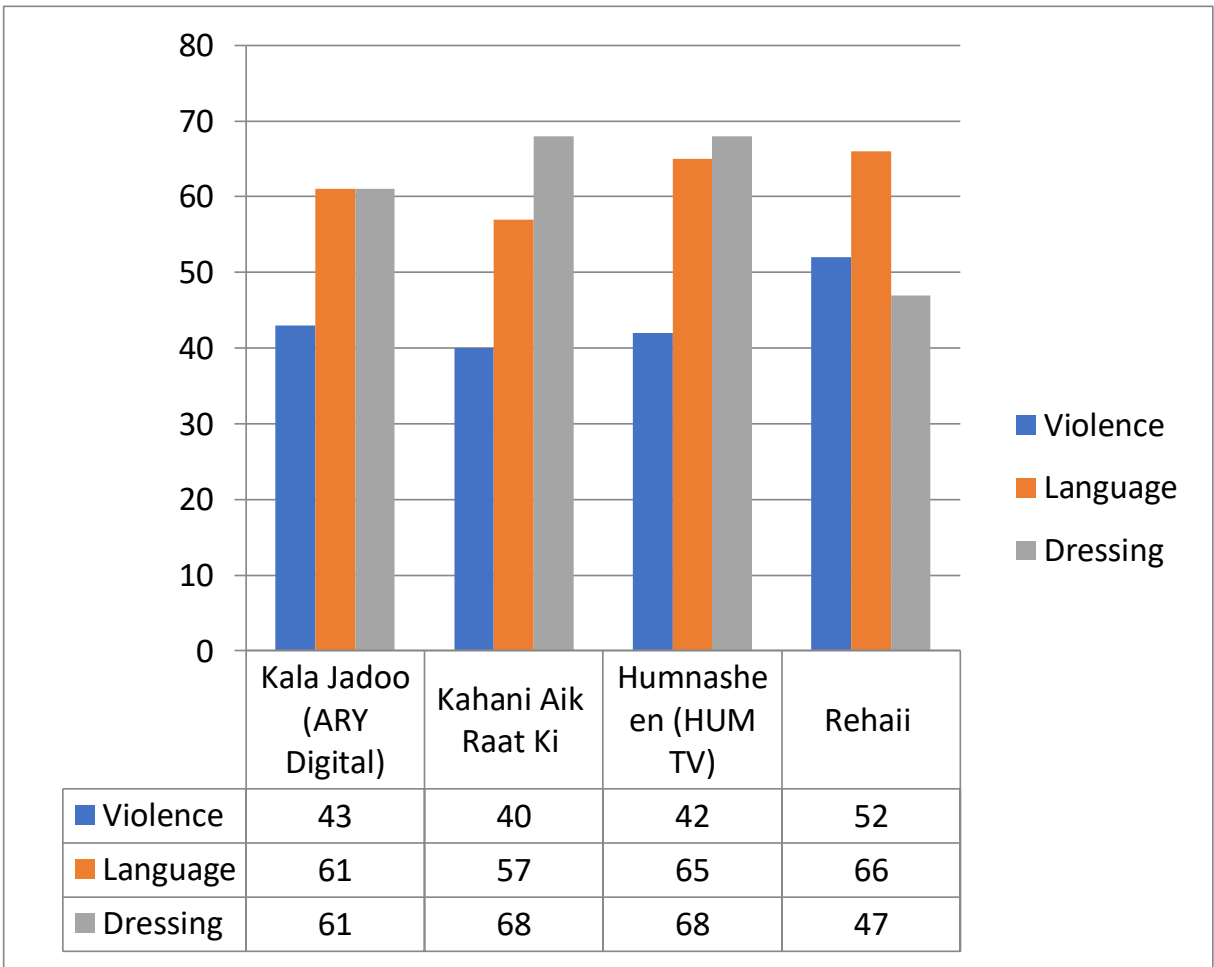

Chart 13: Comparison of ARY Digital and Hum TV for promotion of antisocial and anti cultural behaviors

The comparison shows that all episodes of dramas of HUM TV and ARY Digital promote violence, language and 
dressing. in these dramas. This comparison reveals that HUM TV promotes more violence in their dramas. the physical violence is in the form of slap, drag and push. Whereas ARY Digital dramas promote less physical violence then HUM TV.

This diagram also reveals that the use of bad language is more in HUM TV dramas than ARY Digital dramas. There is significant number of abusive words, bold words and harsh words in HUM TV dramas as compared to ARY Digital dramas. This analysis also reveals that HUM TV promotes more vulgar dressing as compare to ARY Digital. Overall, HUM TV promotes more violence, bad language and vulgar dressing in their dramas as compare to ARY Digital.

\section{Conclusions and Discussion}

\section{RQ1: What is the comparison of use of antisocial and anti cultural elements in dramas of different private TV channels of Pakistan?}

The analysis showed that both channels are responsible for promoting the anti social and anti cultural behaviors in the society. But it is important to note that among the total studied physical violence, $46.8 \%$ was in dramas of ARY Digital and 53.2\% was in the dramas of Hum TV. From the total verbal violence or bad language more than $47 \%$ was in dramas of ARY Digital and about 53\% in the dramas of Hum TV. On the other hand about 53\% use of western or foreign dresses was in dramas of ARY Digital and $47 \%$ use was in the dramas of Hum TV.

\section{H1: Pakistani dramas are likely to be promoting violence in society.}

The analysis shows that there are scenes with violent behaviors in all episodes of both TV channels. ARY Digital used the violent behavior in two dramas for 201 times, that includes 83 physical violence and 118 scenes with bad language or verbal violence. Whereas, Hum TV showed total 225 scenes with violent behavior. These scenes included 94 scenes of physical violence and 131 scenes with bad language or verbal violence. Hence H1 is proved.

\section{H2: Pakistani dramas are likely to be promoting offensive language in society.}

Content analysis of the TV dramas reveled that ARY Digital dramas used bad or offensive language for 118 times in 13 episodes. It makes an average of 9 words per episodes. On the other hand Hum TV dramas used bad or offensive language for 131 times in 13 episodes. It makes an average of 10 words approximately. The results reveled that this number is quiet high and $\mathrm{H} 2$ is proved.

\section{H3: It is more likely that Pakistani dramas are not promoting foreign or western culture through use of dressing.}

The content analysis of TV dramas of ARY Digital and Hum TV showed that there is abundant use of western or foreign dresses. Dramas of ARY Digital used foreign or western dresses for 129 times in 13 episodes. It makes an average of about 10 times in an episode. Whereas, Hum TV dramas used foreign or western dresses for 115 times in 13 episodes. This makes an average of about 9 dresses in single episodes which is quiet high in ratio. Hence $\mathrm{H} 3$ is not proved and it is a null hypothesis.

\section{Discussion}

There was a time when Pakistani dramas were source of entertainment but now days these become only source of frustration. It is proves that Pakistani dramas are promoting violence and anti social or anti cultural elements in society. The show of physical violence is also alarming, in which the female is usually victim and which arises from unequal power relationship between man and woman. Through the exposure to physical and emotional violence, the people are frustrated. As lot of violence display in dramas can ruin our society because which people learn different behaviors from TV. When people watch any type of violence in dramas they are vulnerable to adopt aggressive behavior. 
Behavior of audience can be influenced by the content of media directly or indirectly. Which people learn from dramas they want to behave like this. The dressing in our dramas are very vulgar and language of these dramas are also not up to the standards. Sleeveless dresses, tights and dresses with fitting, that make the body parts prominent and with the emergence of private channels, the quality has worsened and the use of foul language and slang has increased.

The dramas aired on, ARY Digital and Hum TV are notable in this regard where there is a huge presence of unethical language. The use of vulgar dialogues in the drama throws them out of the list of family dramas and families don't want to watch them with all the members of the family as it used to be in the past. These days western influence can be seen all around, but most specifically it can be seen in the way Pakistanis have started dressing up. Whatever fashion becomes popular abroad, it is being adopted by people here, without thinking that it is not meant for their body type or cultural values. Also the Pakistani fashion industry is so inspired from the foreign styles that they don't even hesitate before introducing revealing clothes in their collection. Westernization has been spread throughout our country because of the media. The TV channel shows various characters in the dramas wearing westernized clothes.

\section{Limitations}

- This is a content analysis of four dramas of two channels. This study could be done with more dramas from more channels.

- Discourse analysis of language could also help in understanding the content in a better and scientific way.

\section{References}

Andreason, A. (1995), marketing social change, Jossey-Bass, San Francisco. prr.hec.gov.pk/Chapters/35S-2.pdf Aksoy \& Robins (2003) Gender Role Respresentations In Turkish Television. www.smcm.edu/psyc/_assets/documents/SMP/.../0607-AIkizler.pdf

Andreason, (2007), the media and violence chapter 10: Social Learning, download.aibd.org.my/books/Media_and_Violence.pd

Cantor, J., \& Nathanson, A. I. (1997). Predictors of children's interest in violent television programs. Journal of Broadcasting \& Electronic Media, 41(2), 155-167.

Cashmore, E. (2002). And there was television. Routledge.

Farooq, Q. (2020). Eroticism and Mysteries of Cross-Dressing: Increasing Trends of Male to Female Cross-Dressing in Pakistani Society.

George Gember \& Gross (1976). psychological violence against women as depicted in PTV Urdu Dramas 9(4)

Geen R.G. and Thomas S.L., The Immediate effects of media violence on Behaviour", Journal of social issues 42(3): 7 - 27, P. 74.

Gentzkow and Shapiro (2004) Gentzkow, Matthew and Jesse Shapiro, IMedia, Education and Anti-Americanism in the Muslim World," Journal of Economic Perspectives, $18 \quad$ (2004), $117\{133$. www.lib.uchicago.edu/e/busecon/busfac/Gentzkow.html

Grondelaers, D. G. S. (1995). Looking back at anger. Cultural traditions and metaphorical patterns'. Language and the Cognitive Construal of the World, 82, 153.

Hartley, John (1996) Popular Reality. London: Arnold retrieved from www.connectcp.org/profiles/profile.php?profileid=263

Ingold, T. (2002). Introduction to culture. In Companion encyclopedia of anthropology (pp. 363-383). Routledge. Jamal, H., Tauqir, A., Muqarrab, M., Ramay, A., \& Shahid, S (2018). CULTURAL INVASION \& MASS MEDIA. Khanum, M., \& Khan, K. R. (2000). THE IMPACT OF INDIAN DRAMAS ON LANGUAGE IN PAKISTAN. Science, 51(14), 1306-1320.

Kling, Rob and and Geoffrey McKim. (2000). Not just a matter of time: Field differences and the shaping of electronic media in supporting scientific communication. Journal of the American Society for Information Science, Volume 51, Issue 14, pages 1306-1320, 2000.

Jamie, s (1993). impact of western culture Chapter 2 Literature Review - Higher Education Commission prr.hec.gov.pk/Chapters/35S-2.pdf 
Lavish (2006). Review of literature of changing behavior in dramas www.google.com

Levy, (1982). Social marketing as a tool to stop child abuse', Social Work Now, 8: 5-12

Muhammad (2003) the power of cable television and women status in India faculty.chicagobooth.edu/emily.oster/papers/tvwomen.pdf

Narula Uma (1984). "Dynamics of Development Communication", University of Massachustts, Amhist

Perry, S. D., Jenzowsky, S. A., Hester, J. B., King, C. M., \& Yi, H. (1997). The influence of commercial humor on program enjoyment and evaluation. Journalism \& Mass Communication Quarterly, 74(2), 388-399.

Pamela J. Shoemaker and Stephen D. Reese (1991). "Mediating the message", Long man publishers, London P. 12.

Parvez, M. A., Roshan, R., Riffat, S., \& Qasim, Z. (2009). Psychological violence against women as depicted in ptv Urdu dramas. Global media journal, 2(2).

Raza, S. H., Bakar, H. A., \& Mohamad, B. (2018). Advertising appeals and Malaysian culture norms: Scale content validation. Journal of Asian Pacific Communication, 28(1), 61-82.

Raza, S.H., Abu Bakar, H. and Mohamad, B. (2019), "The effects of advertising appeals on consumers' behavioural intention towards global brands: The mediating role of attitude and the moderating role of uncertainty avoidance", Journal of Islamic Marketing, Vol. 11 No. 2, pp. 440-460. https://doi.org/10.1108/JIMA-11-2017-0134

Raza, S. H., Iftikhar, M., Mohamad, B., Pembecioğlu, N., \& Altaf, M. (2020). Precautionary Behavior Toward Dengue Virus Through Public Service Advertisement: Mediation of the Individual's Attention, Information Surveillance, and Elaboration. SAGE Open. 10(2),1-15. https://doi.org/10.1177/2158244020929301

Robinson, J. P., \& Martin, S. (2008). What do happy people do?. Social Indicators Research, 89(3), 565-571.

Rogers (2000). Geo TV vs. Star plus Dramas and Female Viewers' Perceptions global media journal12 (4) www.ssrc.org/.../\%7B6a130b0a-234a-de11-afac-001cc477ec70\%7D.pdf

Show maker, Reese (1991) psychological violence against women as depicted in PTV Urdu Dramas 9(4)

The Straits Times" (24 July 1993) the Media and Violence chapter 10: Social Learning, download.aibd.org.my/books/Media_and_Violence.pd

Savage, J. (2008). The role of exposure to media violence in the etiology of violent behavior: A criminologist weighs in. American Behavioral Scientist, 51(8), 1123-1136.

Smyth(1954) psychological violence against women as depicted in ptv Urdu dramas global media journal 9(4)

Tomlinson (1991). media imperialism and its effects on culture of Pakistan Global media journal 2 (5) www.aiou.edu.pk/gmj/artical3(Aut-08).asp

Thussu (2000) media imperialism and its effects on culture of Pakistan .Global Media Journal 2 (9) www.aiou.edu.pk/gmj/artical3(Aut-08).asp

Turner and Peterson, (1986) psychological violence against women as depicted in ptv Urdu dramas global media journal 3(5)

Turner C.W. and Peterson Lewis (1986). The Naturalistic Studies of the Long - Term effects of Television violence", Journal of the social Issues 42(3): 51- 73. P. 354.

Tariq, S.i. (2005). "The comparative study of PTV and GEO TV in promoting Pakistani culture", Master's edn, Unpublished master's thesis Mass communication department University of Punjab, Lahore.

Tooba Ghulam, N. (2015). Stereotyping of women in television commercials in Pakistan (Doctoral dissertation, University of Management and Technology, Lahore).

Zia, A. (2003) Consumption of cable television, a research report published in: cable television, A vision of the future. (pp. 56-61). Pakistan Electronic Media Regulatory Authority Islamabad, Pakistan. 